\title{
ANFINO, EL ELOGIO DEL HUMILDE: ALREDEDOR DE LA TEJEDORA DE SUEÑOS DE BUERO VALLEJO
}

\author{
"Todas las esperas saben a tibio \\ siempre acaban en vómito \\ o en sueño placentero. \\ Todas las esperas son verdes: \\ el viento y el sol las van tornando \\ azules o amarillas". \\ Félix Jiménez López: \\ Poemas sin música... y otros ruidos.
}

En La tejedora de sueños, obra de teatro estrenada en 1952, Buero Vallejo nos propone una recreación de mitos clásicos, en concreto, de personajes de La Odisea, harto conocidos a través de la tradición literaria.

$\mathrm{Su}$ actitud coincide con el resto de los autores contemporáneos ${ }^{1}$ : ofrecernos personajes poetizados en la literatura griega, impregnados de una postura desmitificadora ${ }^{2}$ comprendiendo a través de esta línea la persistencia del mito clásico y su eficacia actual.

Buero Vallejo ahonda en estos mitos mostrando facetas desconocidas que cambian de forma radical su significado, reelabora totalmente el relato para ofrecernos una nueva lectura basada en la verdad interior y la verdad histórica de los personajes, y rechazando cualquier tipo de versión idílica porque ésta es deformadora.

Algunas de estas transformaciones no son gratuitas porque ciertos versos de La Odisea ya nos muestran un conflicto subterráneo señalado por el autor en el "Comentario" a su

1 La influencia de La Odisea en la literatura contemporánea es evidente: El retorno de Ulises de Torrente Ballester y ¿Por qué / corres, Ulises? de Antonio Gala son dos ejemplos de dramaturgía contemporánea. Álvaro Cunqueiro con su novela Las mocedades de Ulises nos permite sumergirnos en un atractivo mundo de fábulas y en poesía, otra referencia es Gabriel Celaya: "La fábula de Ulises" conjunto de nueve poemas que relatan el viaje y el retorno, incluídos en Cantos y mitos.

2 El propio autor insiste en este aspecto y nos aclara el vocablo: "desmitificar es saludable y necesario, pero no es, creo, la fómula definitiva... Desmitificar es relativamente fácil; la dificultad - y el hallazgo - es volver a mitificar". 
obra y por algunos helenistas como Lasso de la Vega que corroboran esta doble realidad del mito. ${ }^{3}$

Del poema griego, Buero Vallejo recibe prácticamente toda la trama aunque altera el argumento mítico: Penélope, reflejo de fidelidad, es transformada en una mujer que ya no desea a su marido, anhela olvidar un pasado heróico y está dispuesta a construir una nueva vida al lado de otro hombre, Anfino, el Anfinomo griego.

Anfino es un pretendiente aparentemente irrelevante en La Odisea. Buero Vallejo toma las sencillas notas que nos ofrece Homero para reelaborar al personaje de una forma total y absoluta y cobrar, así, una dimesión insólita. Sobre él reposa todo el plano poético de esta obra teatral. El dramaturgo nos descubre un héroe donde antes no existía y desenmascara un héroe ya constituído: Ulises.

Anfino, de típica filiación bueriana, pertenece a la galería de personajes contemplativos, ${ }^{4}$ un hombre que duda, con conciencia clara de sus limitaciones y de la sociedad que vive, que sueña, como Penélope, con una realidad diferente pero fracasa en sus relaciones con los demás porque no posee la capacidad necesaria para afrontar los obstáculos de su medio.

Es el pretendiente que posee menos riquezas pero es el mejor como individuo, y no desea un matrimonio encaminado a conseguir el reino de Ítaca, cada vez más ruinoso, sino que desea a Penélope de forma sincera.

A la vez, motiva en la mujer el más alto concepto de sí misma y eleva su conciencia porque el amor y la bondad de Anfino la ennoblecen, enriquecen su espíritu... y su soledad:

"Él no era cruel y no me hubiese perdonado la crueldad". 5

"Vosotras gemís por las noches, cuando los pretendientes os toman para

distraer su espera. ¡Y ella gime sola!"6

El dramaturgo trata de la vida humana en una dimensión metafísica de autencidad. No es una heroicidad exterior, de hazañas brillantes y extraordinarias, sino una heroicidad consigo mismo, en lo más recóndito del ser humano. ${ }^{7}$

3 Lasso de la Vega, Helenismo y literatura contemporánea. Madrid, Prensa Española, 1967.

4 La antinomia de personajes activos-contemplativos nos la aclara Ricardo Doménech, gran estudioso de Buero Vallejo. El teatro de Buero Vallejo. Madrid, Gredos 1979.

5 Antonio Buerro Vallejo, La tejedora de sueños. Llegada de los dioses. Edición a cargo de Luis Iglesias Feijoo, Madrid, Cátedra 1985, p. 199.

6 Ibídem, p. 112

7 Luis Díez del Corral, La función del mito clásico en la literatura contemporánea. Madrid, Gredos 1974, p. 233. 
Pero Homero nos da una perspectiva, la exaltación de Ulises. En el poema griego, prácticamente todos los personajes están en función de Ulises, pero en la obra teatral se nos presenta a aquel con un sentido diferente, un hombre pusilánime e inseguro al que el tiempo y el espacio le han quitado todas las telarañas. Veinte años son demasiados para que su memoria no se deteriore, sobre todo en la mente de Penélope que ahora ya no es tradicional símbolo de la espera. Buero Vallejo nos presenta ya desde el primer acto el desnudo espiritual de esta mujer tejiendo silenciosa y ayudada por sus esclavas mientras éstas emiten un canto monótono pero artificioso como descubrimos cuando nos acercamos al clímax de la obra. Ya no es ese ser casi sobrenatural que nos legó Homero, queda convertida en una mujer que ha sufrido los veinte años, día tras día y noche tras noche, la angustiosa espera de un presente mejor.

Reflejo de su insatisfacción y su tensión acumulada es su envidia por Helena. Ella ha sido capaz de suscitar una guerra. Ulises, incluso, cuando retorna al reino, llega a justificar esta guerra:

"...Helena es tan hermosa que..., incluso una guerra como la de Troya, puede comprenderse por ella... Pues yo he envidiado a Menelao, y a Paris y a todos los que tuvieron a Helena. Yo la he visto en Esparta y he comprendido el rapto y los crímenes, y me he sentido, por primera vez, ambicioso de poder $\mathrm{y}$ riquezas para lograr a esa mujer". ${ }^{8}$

Estas frases suponen para Penélope una fuerte agresión psicológica que surte su efecto porque Ulises juega con el pasado de Helena convirtiéndolo en presente e intenta que permanezca bella aún ahora, cuando sabemos, que es decrepitud y vejez y fue causante de una guerra estúpida.

Mientras, Penélope, ofendida en su vanidad de mujer, se encierra en el templete para tejer y destejer sus sueños: Helena vencida, demacrada por el paso del tiempo, Ulises que no regresa y una vida por realizar al lado del hombre que la quiere. Y así, ríe neurótica, cada vez que su nodriza Euriclea le comunica la devastación de su hacienda:

"Se que cuando alguna nueva desgracia nos abate...

Cuando te anuncian que se acaban las reses, o que

hay que aguar el vino escaso, o que esos bandidos

te robaron tus joyas, entonces... no gimes. Ríes."

8 La tejedora de sueños. Llegada de los dioses... p. 123.

9 Ibídem, p. 116. 
Esta actitud refleja en Penélope el deseo de que renuncien los pretendientes. ${ }^{10} i$ Con el vehemente deseo de que permanezca el que realmente la desea, o el menos ambicioso? A su manera, ella también defiende su vida afectiva.

Pero como Penélope no es el símbolo de virtud que le ha atribuido la leyenda ${ }^{11}$ y sí un ser con sentimientos contradictorios, también aparece su deseo de prolongar la situación de los pretendientes, con la ilusión de recuperar su juventud, revivir su existencia, efectuar su particular guerra de Troya, intención que confiesa a Anfino:

"Helena nos quitó a nuestros esposos. Por esa... puerca las mujeres honradas hemos quedado viudas, condenadas a hilar y tejer en nuestros fríos hogares.

A consumimos de vergüenza y de ira porque los hombres razonaron que había que verter sangre, en una guerra de diez años, para vengar el honor de un pobre idiota llamado Menelao. Así pensaba yo cuando vinísteis a pretenderme. ¡Ah, cómo respiré! ¡Treinta jóvenes jefes, hoy viejos o muertes, conducían nuestros ejércitos en Troya por causa de Helena. ¡Y treinta jóvenes jefes, hijos de los anteriores muchos de ellos venían a rivalizar por mí! ¡Por mía, por Penélope! ¡No por Helena, no! Sino por Penélope. Era mi pequeño desquite... Mi pequeña guerra de Troya. Me sentía vivir. Había que hacer durar, como fuese, esta lucha vuestra, que alimentaba mi amor propio herido, que me daba seguridad de mi propia existencia, como no la había vuelto a sentir desde... que Ulises me ganó a otros diecinueve príncipes hace muchos años." 12

Pero su guerra de Troya no será ganada porque Ulises no lo permitirá. Su vida quedará en unos sueños que deshace cada noche en el intento de evitar un conocimiento público de los mismos.

Buero Vallejo introduce en la obra un personaje original que nos da la pauta argumental de la obra: Dione, esclava sabedora de que Penélope gime por el pretendiente de quien ella misma también está enamorada. La esclava es la única que ha descubierto el alma de Penélope en el plano del ensueño, porque desea que su reina se decida pronto, le comunica su juego a Anfino:

10 En el poema griego son ciento ocho los que han aguardado una decisión durante tanto tiempo. Homero, La Odisea. Traducción de Lluís Sagalà, Barcelona, Bruguera 1982, Canto XVI, versos 247-251, p. 257.

11 El mito de Penélope no se agota en La Odisea.

12 La tejedora de sueños. Llegada de los dioses... p. 157. 
"...Tú debes ser el hombre de esta casa y necesitas a una mujer verdadera a su lado. $Y$ nadie, sino yo puede ser la verdadera mujer de esta casa... cuando tú seas el hombre.

Nuestro juego debe hacerse pronto, si queremos, todavía..., poder administrar algo." 13

Oferta que éste rechaza porque es honesto, y Dione, menospreciada, es la que se encarga de comunicar a los pretendientes la estafa de su reina que es, por otra parte, revelación pública de su intimidad, de sus deseos, lo que la historia no ha contado. ${ }^{14}$

Porque Penélope sueña con un futuro diferente ya no desea el regreso de su marido. Intenta olvidar su vida anterior para luchar por su placer y su satisfacción.

Pero Ulises vuelve, embaucador y mentiroso, disfrazado de extranjero. A lo largo de la obra hay diversas alusiones a su tiranía. Incluso la misma Penélope emite algún que otro comentario irónico:

"Yo soy la fiel Penélope... La prudente esposa del no menos prudente Ulises.

Si el volviera, a todos nos sobraría prudencia." 15

Penélope se enriquece personalmente y aprende a criticar al héroe cuando regresa para retomar las cosas en el mismo punto donde las dejó hace veinte años. Y sin embargo la casta mujer no es capaz, no sabe vivir su momento. La aparente venganza del héroe impide que Penélope consiga hacer realidad sus sueños porque su crítica únicamente se queda en palabras, no sabe rebelarse. El héroe con su marcha abatió a su compañera, él mismo con su vuelta, la llena de tristeza y sumisión. Y Penélope se aflije:

"...La vida llora por los míos, Euriclea. La vida que no he vivido. Porque toda mi vida ha sido destejer... Bordar, soñar... y despertar por las noches, despertar de los bordados y de los suños... ¡Destejiendo!"16

13 Ibídem, p. 152.

14 Al respecto, Gabriel Celaya en su libro de poemas "La fábula de Ulises" nos refiere su particular interpretación de la historia del héroe. $Y$ en su Proemio:

"Canto el vivir del cuento; las mentiras de Ulises que acabaron al fin por volverse verdades más llenas de sentido que los hechos reales. ¿Qué nos dicen los hechos desnudos por sí mismos? Lo que mueve la Historia son interpretaciones de algo que nadie sabe cómo fue si es que ha sido."

Gabriel Celaya, Cantos y mitos. Madrid, Visor 1984, p. 67.

15 La tejedora de sueños. Llegada de los dioses... p. 141.

16 Ibídem, p. 143. 
En este universo de ensoñación Anfino se manifiesta con un carácter amable, desmitificado y a la vez mitificado sobre lo que aparecía en la tradición literaria como poco significativo, configurándose el nuevo héroe de la tragedia moderna, navegante en un mar agitado y trazando el sendero con su fuerza personal.

En la prueba del arco, - de nuevo los pretendientes deberán medir su vigor físico Anfino no desea obtener ventajas a pesar de que Penélope le propone tenderlo horas antes del certamen y le revela que ella misma ayudó a Ulises en su momento, pero Anfino desea luchar sin ventajas:

"¿No comprendes que no podría probar aquí, solo, frente a ti? No me atrevería a mirarte más a la cara. ¿No lo comprendes?"17

Es así como Penélope lo ha soñado y por los dos no sucumbirá al oprobio, es más honesto luchar limpiamente.

Ulises no desea arriesgarse. El héroe de La Odisea ha desaparecido y la honradez que caracteriza a Anfino no es la suya. Continuamente aparece la oposición activocontemplativo en estos dos personajes.

Ulises, porque es la mejor representación de un ser primitivo, acompañado de las Furias vengadoras, conseguirá su objetivo pero también con la supuesta venganza alcanzará su ruina espiritual. Con su dureza: "Terminaron tus sueños, mujer," 18 despierta a Penélope a la cruel realidad, su marido ha regresado para vengarse, pero no arriesga su vida, mata a unos enemigos indefensos. Con Anfino adoptará otra actitud por la amistad que le une con su padre y porque es un hombre valiente, no corre ni se atemoriza, espera pacientemente la muerte. Ulises le dará la oportunidad de defenderse porque reconoce sus valores:

"Sabes morir... Ninguno de esos valía lo que tú."19

Anfino recibe la muerte de forma enérgica y sus últimas palabras tienen un profundo significado en la obra. Reflejan el exterminio que ha sido realizado, es la voz de su conciencia:

"Yo también defendía a Penélope, Ulises. Pero acepto morir en tus manos. Me matas porque tú estás muerto ya; acuérdate de lo que te digo. La muerte es nuestro gran sueño. Morir en vida es peor; prefiero hacerlo ahora.

Gracias por tu flecha, Ulises. La muerte es nuestro gran sueño liberador... Gracias por tus sueños, Penélope."20

17. Ibídem, p. 176.

18 Ibídem, p. 189.

19 Ibídem, p. 193

20 Ibídem, p. 194 
Con la venganza llega la muerte pero no únicamente de los pretendientes, también de los sueños y de la vida misma. La acusación de Anfino es cierta. Ulises ya ha muerto. Y no podrá vengarse con la desaparición de Anfino porque en el ensueño del humilde quedará el recuerdo de una mujer eternamente joven y bella. Es Anfino quein hace comprender muy pronto a Ulises la certeza de sus últimas palabras. La heroicidad será sustituída por nuevas actitudes que vislumbran la bondad y la humildad. El nuevo héroe configurado por Buero Vallejo, Anfino, nos indica una forma auténtica de vida, desde el interior, ese camino monótono en el que no encontramos nuestras propias decisiones, nos impone mirarnos en el interior, girar lentamente hacia nosotros mismos, sin esperas, porque éstas se alteran con el transcurrir de la vida...

Ulises no ha logrado su venganza. Sólo le queda descubrir su engaño y con él la declaración del actual estado físico de Helena:

"- En cuanto a Helena... Te he mentido. ¡Ya no hay Helena, mujer! ¿Ya no existe!

$-¿$ Murió?

- No. Pero está fea y vieja."21

Penélope ha luchado contra un fantasma, - "Ha envidiado inútilmente" - y la degradación de Helena es la suya propia. También la de Ulises que ha llegado a Ítaca disfrazado de extranjero, inseguro, porque se sabe viejo y lleno de arrugas. El castigo, la venganza de Anfino será el desconocimiento para ambos esposos. Ulises será testigo de la senectud de Penélope, el héroe está realmente vencido porque Anfino se ha llevado todo para siempre.

Porque ya no está Atenea para rejuvencer a sus preferidos, la única posibilidad de Ulises es salvar la fama, el prestigio, pues ya nadie le recordaba cuando regresó a su Ítaca y ya no puede realizar nuevos viajes ni aventuras porque está viejo.

Sólo le queda ser glorificado como pretende. Ha regresado para perpetuar su nombre. Los sueños de Penélope contenidos en el sudario serán quemados junto al cuerpo de Anfino en la pira de festines. Anfino se lleva todo consigo. Y el coro final ofrecido también al principio de la obra es un nuevo artificio que sólo nos transmite la versión "oficial" de los hechos:

\footnotetext{
"Penélope nos dice desde Grecia:

cinco, diez, veinte años no son nada.

El amor no envejece y nuestra sangre

sabe esperar la vuelta del amado.

Cual roca poderosa es la hembra fuerte.

El esposo partió pero la reina

su palacio y su lecho ha defendido,
}

21 Ibidem, p. 196. 
cual nuevo Ulises sin olvidar nunca.

Penélope fue sola, y circundada

estuvo de peligros y deseos.

Más sólo para Ulises vive ella.

Y no caerá cual otra Clitemnestra.

Tejía y destejía durante años

para burlar así a los pretendientes.

Ella bordó sus sueños en la tela.

Sus deseos y sueños son: ¡Ulises!"22.

Cuando nos acercamos al clímax de esta obra dramática comprendemos la abismal diferencia entre apariencia y realidad.

Ahora el inhumano Ulises se dedicará a cobrar tributos a las gentes, cual opresor, para recuperar su decadente reino. Y mientras... Penélope esperará la rapsodia de Anfino que... nunca llegó a componer.

Povzetek

AMFINOM, HVALNICA PONIŽNEGA:

O TKALKI SANJ (LA TEJEDORA DE SUEÑOS) BUERA VALLEJA

Buero Vallejo, španski avtor tega stoletja, je $\vee$ Tkalki sanj (La tejedora de sueños) oživel osebe iz Odiseje.

Vendar Penelopa ni zvesta žena, ki nestrpno pričakuje junakovo vrnitev; pa tudi vedenje drugih oseb ni takšno, kakršnega poznamo iz klasične literaure. Amfinoma, nepomembnega prosilca $v$ Homerjevi pesnitvi, pisatelj dojema kot ponižnega in razumnega človeka, ki pa na koncu nima toliko moči, da bi lahko spremenil stvarnost. In medtem ko Penelopa venomer znova tke in razdira svoje sanje, prispe Odisej, da bi se maščeval in razblinil prazna upanja. Vsi so nekaj izgubili med čakanjem, kajti samo spomin ne more nadomestiti stvarnosti. In ostane samo še rešitev slave - to, kar nam je zapustila legenda. Mirni Amfinom pa sprejme smrt in s seboj odnese spomin na večno mlado Penelopo.

22 Ibídem, pp. 204 y 205. 